\title{
ANÁPOLIS E OS EXEMPLARES HABITACIONAIS DE CARATER MODERNISTA
}

\section{Anápolis And Residential Examples By Modernist Character}

\section{Sandra Catharinne Pantaleão}

Arquitetura e Urbanismo do Programa de Pós Graduação da Universidade de Brasília sandrinhapanta@gmail.com

\section{Celina Almeida Fernandes Manso}

Arquitetura e Urbanismo do Programa de Pós Graduação da Universidade de Brasília celina.manso@hotmail.com

\section{Pedro Henrique Máximo Pereira}

Arquitetura e Urbanismo do Programa de Pós Graduação da Universidade de Brasília arqurbarv.pedrohenrique.mx@gmail.com

\section{Daniela José da Silva}

Arquitetura e Urbanismo do Programa de Pós Graduação da Universidade de Brasília danijdesigner@gmail.com

\section{RESUMO}

Observa-se no território goiano, entre as décadas de 1930 e 1970, processos de modernização vinculados à construção de duas cidades planejadas: Goiânia, capital do Estado de Goiás (1933) e Brasília, capital federal (1960). O crescimento populacional expressivo e a chegada da ferrovia também são elementos propulsores dessas mudanças. Como resultado do desejo de modernização, algumas cidades, em especial Anápolis tiveram sua paisagem urbana modificada em que se observa uma produção arquitetônica pouco estudada e que permite avaliar distintos modos de modernização. A partir do levantamento de dados e mapeamento de exemplares habitacionais localizados na cidade de Anápolis, pode-se visualizar três categorias distintas de caráter modernista: referenciados, apropriados e popularizados. São fragmentos de modernidade que ajudam a compreender de que maneira o diálogo entre arquitetura e cidade permite analisar as manifestações de renovação e racionalidade na difusão do ideário moderno. Diante da lacuna documental e histórica este trabalho propõe-se a sistematizar os exemplares ainda inéditos.

\section{Palavras-chave}

Modernidade; Anápolis; Ideário Moderno; habitação. 


\section{ABSTRACT}

On goiano territory, especially in Anápolis, it is observed a modernization process between 1930 and 1970 when new towns were built: Goiânia, the capital of the State Goiás (1933) and the federal capital, Brasilia (1960). This is a period that Anápolis experienced a significant population growth and the progress was intensified by the arrival of the railroad (1935). As result of modernization's desire its landscape was transformed where it is possible observed an architectural production little studied but that allows evaluate a distinct modernization process. From the survey dice and mapping of residential examples location on Anápolis, it was possible divide the modernist architecture of Anápolis in three categories: legitimate, distinctive and popularized. The examples found were considered as fragments by modernity and these categories help us to understand how the dialogue between the city and habitation can reveal signs of renewal and rationality in the consolidation and dissemination of modern ideas. Faced with the historical and documentation gap about architecture modernist in Anapolis, this work aims to reveal these still unpublished architectural examples in the historiography of modern architecture and urban planning.

\section{Key words}

Modernity; Anapólis; Ideation Modernist; habitation.

\section{INTRODUÇÃO}

O ideário moderno em Anápolis se propagou entre as décadas de 1930 e 1940, quando se observam várias renovações urbanas no tecido urbano existente e a implantação de novos loteamentos com características modernistas. E o desejo de modernização foi intensificado com a construção Goiânia e Brasília, constituindo-se um eixo de propagação das ideias vigentes nos centros urbanos mais consolidados. Entre 1930 e 1970 dezenas de edificações foram demolidas, outras tantas foram construídas com uma estética diferenciada em relação à arquitetura colonial: edifícios públicos com elementos Art Déco e edifícios habitacionais influenciados pelas características modernas.

A inserção da cidade no contexto de modernidade iniciou-se com a instalação da ferrovia, em 1935, que alavancou a economia local. O papel de Anápolis 
como entreposto comercial foi intensificado, uma vez que a ferrovia permitiu uma comunicação maior entre a região sul do Estado, que recebia influências diretas do Triângulo Mineiro e, por consequência, dos grandes centros urbanos da época com a região da antiga capital do Estado, Vila Boa de Goiás, localizada mais a norte.

A ferrovia contribui para a difusão de ideias e troca de experiências, à medida que imigrantes chegavam à região e a população local passava a frequentar outros centros urbanos e passaram a ter necessidade em renovar e modernizar Anápolis, principalmente pela pujança econômica das décadas de 1930 e 1960, como local de suporte às duas cidades novas implantadas em território goiano.

Todos esses fatores desencadearam o processo de urbanização dos sertões no interior do Brasil Central e a possibilidade de modificar a situação de "atraso regional" da cidade de Anápolis, cunhando uma mudança cultural e modernização, trazendo consigo a expressão de modernidade no edifício da estação (figura 1).

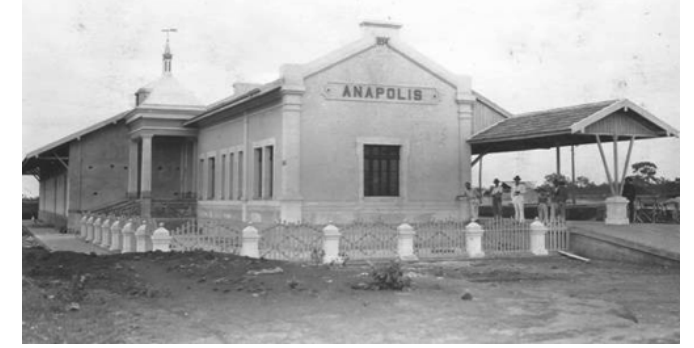

Figura 1: Estação Ferroviária (1935).

Fonte: Arquivo Museu Histórico de Anápolis, 2011.

O ostracismo econômico ficou para trás, juntamente com a demolição de casarios na área central da cidade, conferindo a cidade uma nova história. Como ponto final dos trilhos férreos, a cidade transformou-se em entreposto comercial, integrando diversas regiões do Estado de Goiás, seja com a nova capital quanto com os demais centros urbanos do país, dinamizando a economia de Anápolis, que tornouse importante pólo agroindustrial já na década de 1950. A ferrovia permitiu um fluxo mais rápido nas transações comerciais, seja pelas importações de produtos manufaturados quanto pela exportação de bens primários. Essa troca engendrou também a penetração de novas ideias e valores culturais para a cidade.

Essas transformações em Anápolis, entre as décadas de 1940 e 1950, refletem o impulso econômico que a construção de Goiânia (1933) e Brasília (1960) proporcionaram à cidade. Com a construção dessas cidades, Anápolis teve um grande crescimento populacional, alterando os hábitos dos moradores e surgindo novos. Com esse aumento, a cidade teve um "bombardeio" de ideias modernistas, nos aspectos culturais, econômicos, habitacionais e comerciais. 
A partir dessa (re)configuração urbana, os exemplares modernistas se alastram e complementaram a dinâmica transformadora de Anápolis entre as décadas de 1940-1970.Nota-se que as principais alterações ocorreram tanto pelas transformações do tecido urbano, como também pelos exemplares habitacionais e edilícios de características modernistas. Podemos dizer, retomando às questões abordadas por Segawa (1999), que a migração de arquitetospara as áreas interioranas do país contribuiu para a difusão do pensamento modernista e sua adequação e absorção conforme a realidade de cada uma destas áreas. Muitos desses profissionais, incentivados pelas cidades novas implantadas no interior do Estado, Goiânia e Brasília, também aturaram em outras localidades. Em Anápolis não foi diferente, especialmente pela comunicação permitida pela ferrovia, os arquitetos e urbanistas puderam participar de parte das transformações de algumas cidades, inserindo as ideias que circundavam nos grandes centros urbanos bem como a propagação das ideias corbusianas, difundidas no circuito acadêmico.

A produção arquitetônica registrada no Estado de Goiás, segundo Vaz e Zárate (2005), indica a presença de profissionais migrantes e que não se limitou apenas à nova capital do Estado. Anápolis, por representar um centro comercial de relevância para a consolidação de Goiânia também fora influenciada por este ideário moderno. Arruda e Pereira (2008) comentam a atuação profissional de arquitetos e engenhos migrantes, principalmente de São Paulo, Rio de Janeiro e Belo Horizonte.

Elder Rocha Lima, formado pela Faculdade Nacional de Arquitetura no Rio de Janeiro, que teve grande atuação em Goiânia também é um dos profissionais de relevância para a difusão do ideário moderno, com um número considerável de exemplares modernistas, em que se destaca a Residência de João de Faria (1958) (figura 2). Outros arquitetos e engenheiros, oriundos desses centros urbanos mais consolidados, também participaram da modernização de Anápolis. João Alves Toledo, engenheiro do Rio de Janeiro foi responsável pelo projeto do Bairro Jundiaí (1949), José Fernandes Valenteparticipou da execução daEstação Ferroviária de autoria do Engenheiro Wenefredo Barcelar Portela, responsável pela implantação da ferrovia. Esses profissionais também, conforme registros de jornais da época, foram responsáveis por diversas residências na área central da cidade. Uma delas, em que se destaca, em frente à Estação Ferroviária, na Praça Americano do Brasil, foi a primeira a ser construída em concreto armado na década de 1940 na cidade. Tambémregistram-se edifícios habitacionais unifamiliares elaborados por Lúcio Pinheiro, formado em Minas Gerais, como a Casa Hanna Hajar da década de 1970 (figura 3). Outra informação apurada, ao longo da pesquisa, trata-se de um exemplar 
atribuído ao escritório de Oscar Niemeyer (figuras 4 e 5). Cita-se também a presença de Mário Evaristo de Oliveira, engenheiro formado em Minas Gerais, reitor da Universidade Federal de Goiás e que desenvolveu diversos projetos residenciais em Goiânia e Anápolis, bem como projetos de infraestrutura urbana nas duas cidades.

A partir daí, pode-se apontar uma arquitetura referenciada, como legitimação da modernidade, mediante a difusão do conhecimento de um profissional habilitado. Os exemplares mencionados possuem em suas fachadas elementos característicos da arquitetura modernista. O exemplar elaborado por Elder Rocha Lima possui também painéis em azulejos, aproximando-se das propostas modernistas brasileiras da década de 1930. Já o exemplar de Antônio Lúcio Pinheiro aproxima-se mais das características brutalistas, em que se destacam elementos em concreto.

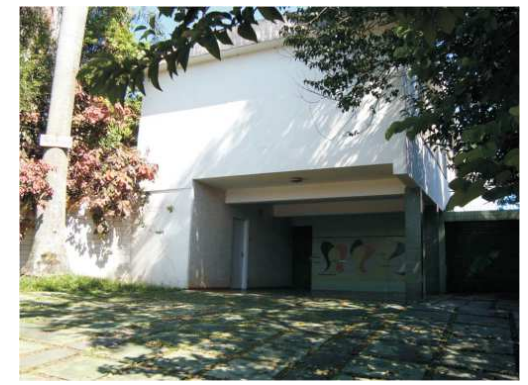

Figura 2: Residência João de Faria.

Fonte: Lima, Camila Loiola, 2011.

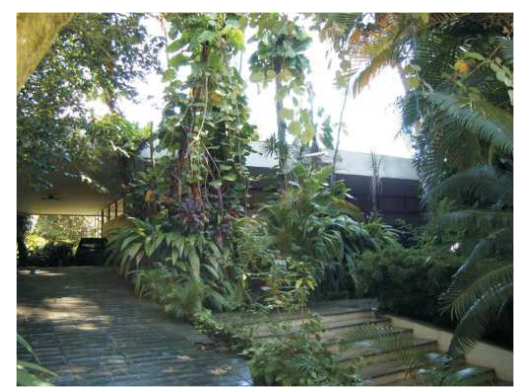

Figura 4: Fachada Residência atribuída ao escritório de Oscar Niemeyer.

Fonte: Lima, Camila Loiola, 2011.

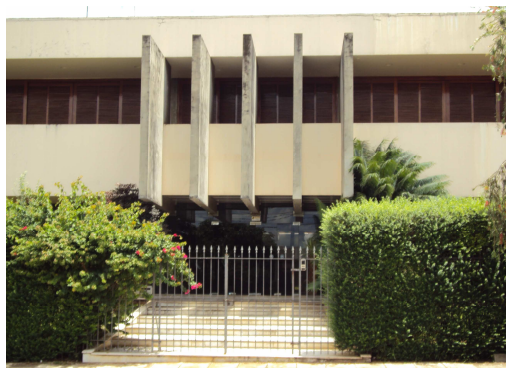

Figura 3: Residência Hanna Hajar. Fonte: Pantaleão, 2010.

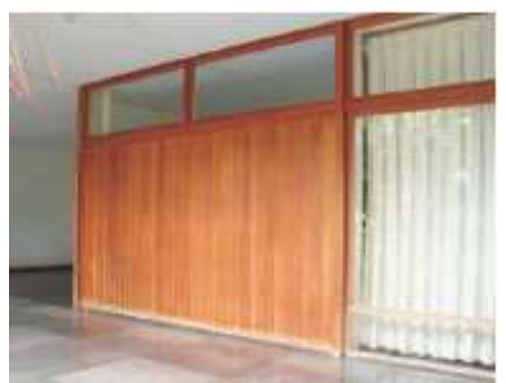

Figura 5: Painel em Madeira como divisória em residência atribuída ao escritório de Oscar Niemeyer.

Fonte: Lima, Camila Loiola, 2011.

Por outro lado, à medida que estas ideias eram edificadas, surgiam outros exemplares com elementos característicos dos princípios corbusianos, mesclados às ocupações tradicionais da casa brasileira, alterando-se a paisagem urbana da cidade. À medida que um número considerável de exemplares eram construídos no centro da cidade, com projetos desenvolvidos por profissionais, observa-se a apropriação de alguns destes elementos modernistas em exemplares categorizados por referenciados. Considerou-se, que algumas vezes, estes exemplares mantinham elementos vernaculares, tais como técnicas construtivas, telhado em quatro águas, 
conjugados com elementos de fachada modernistas, como platibandas ou revestimentos decorativos em gesso.

Outra manifestação identificada concentra-se na utilização de elementos arquitetônicos de maneira popularizada: algumas características são reforçadas e alastram-se nas áreas circundantes ao centro histórico da cidade, em que a composição formal fugia das proporções ideais e, muitas vezes, eram resultado de autoconstruções.

Ao evidenciar que a construção da cidade, em seu período de modernização (1940-1970), perpassou as escalas arquitetônica e urbana, vislumbra-se como os fenômenos socioculturais contribuíram para a formação da paisagem cultural, uma vez que verifica-se um processo de modernização em Anápolis em que os exemplares habitacionais tiveram papel de disseminação desse desejo. Seja em suas feições mais referenciadas; seja pela apropriação e difusão do ideário modernista à medida que a própria população erguia suas residências, assimilando os elementos e/ou reinterpretando-os. De modo geral, assistiu-se durante o período de pujança econômica da cidade, a proliferação de exemplares no tecido urbano, como expressão máxima dos ideias modernistas e afirmação socioeconômica.

Em Anápolis, o processo não foi diferente. Houve não apenas a difusão da arquitetura moderna como também a busca pelo embelezamento urbano modificandosea área centraldefinida como centro histórico ao redor das Igrejas Santana e Bom Jesus pelo tratamento paisagístico das áreas públicas, conformando praças urbanizadas. Os edifícios coloniais foram pouco a pouco substituídos por exemplares com feições modernas, além do alargamento de vias e a preocupação com a estética urbana, expressão dos movimentos urbanísticos da virada do século XX.

Além da área central, núcleo original da cidade, percebe-se que o ideário modernista alcançou uma dimensão urbana. Isso pode ser observado pelo loteamento do bairro Jundiaí, elaborado por um engenheiro carioca e visava proporcionar à população mais abastada um bairro com ruas mais largas e sinuosas, áreas destinadas ao lazer, bem como lotes maiores do que aqueles encontrados no centro da cidade. O bairro-jardim foi proposto em 1949 e lançado em 1953.

Para tanto, a pesquisa analisou os exemplares habitacionais unifamiliares, situados no centro da cidade e no Bairro Jundiaí a partir de três categorias: arquitetura moderna referenciada, arquitetura moderna apropriada e arquitetura moderna popularizada.

Isso ocorreu à medida que os estudos e levantamentos de campo apontaram a presença não só de exemplares legítimos do modernismo, mas também a forte 
presença de edifícios que tiveram com maior ou menor rigor sua influência. Com isso se fez necessária à divisão nessas três categorias a fim de sistematizar o estudo proposto. Os exemplares foram categorizados em Arquitetura Moderna Referenciada, pensada e executada por arquitetos e engenheiros de formação modernista; Arquitetura Moderna Apropriada, onde se verifica a mescla entre tradição vernacular, quanto à ocupação do lote e técnicas construtivas e o tratamento estético da fachada com elementos modernistas; e a Arquitetura Moderna Popularizada, que se deu pela apropriação de alguns elementos típicos desta arquitetura de forma aleatória e arbitrária. A análise pautou-se pela percepção visual dos exemplares, visto que o interesse da pesquisa centra-se no papel dos exemplares para a paisagem urbana.

Com isso, foram avaliadas as fachadas dos exemplares e também a ocupação do edifício no lote, verificando-se as características tradicionais vernaculares e modernistas. Foram categorizados como referenciada os exemplares que possuíam recuo no lote - frontal e lateral, acessos por rampas ou escadarias, elevando-se o edifício do lote, proporção entre os elementos compositivos da fachada com intenções plásticas, utilização de formas livres e proteção solar, presença de jardim na parte frontal do lote e revestimentos tais como azulejos característicos da época. Diferentemente das características morfológicas apontadas por Reis Filho (2004).

Os exemplares de arquitetura moderna apropriada evidencia, em suas fachadas, o emprego de elementos modernistas, mas mantém uma ocupação do lote próxima à colonial, principalmente das décadas de 1950, contando apenas com recuo lateral, aproximando-se das características ecléticas descritas pelo autor. Também, verifica-se menor unidade compositiva, em que é possível reconhecer as influências, mas com menos rigor estético que aquelas referenciadas.

A arquitetura moderna populariza foi atribuída aos exemplares que possuem menor unidade compositiva e sobreposição de elementos sem quaisquer relações compositivas dentre os princípios da linguagem modernista. Tampouco percebe-se uma preocupação formal e presença de projetos com autoria, sendo, muitas vezes, exemplares construídos pela mão-de-obra que construíra os exemplares de caráter referenciado.

Estudando os elementos da arquitetura moderna internacional e brasileira, chegou-se a uma metodologia para identificar os representantes das três categorias identificadas em Anápolis. Lembrando que estas não são características rígidas, apenas uma forma de facilitar a leitura baseada na análise visual de elementos que se repetem, conforme apresentado no quadro 1. 
Quadro 1:Sistematização e caracterização dos exemplares especializados na cidade de Anápolis. Fonte: Arquivo dos autores, 2011.

\begin{tabular}{|c|c|c|}
\hline $\begin{array}{l}\text { Arquitetura Moderna } \\
\text { Referenciada }\end{array}$ & $\begin{array}{c}\text { Arquitetura Moderna } \\
\text { Apropriada }\end{array}$ & $\begin{array}{l}\text { Arquitetura Moderna } \\
\text { popularizada }\end{array}$ \\
\hline $\begin{array}{l}\text { - Formas livres e flexibilidade } \\
\text { de volumes; } \\
\text { - Proteção solar; } \\
\text { - Curvas e estrutura com } \\
\text { intenção plástica; } \\
\text { - Edificação solta no lote; } \\
\text { - Presença de jardim; } \\
\text { - Pilares aparentes; } \\
\text { - Azulejos no revestimento; } \\
\text { - Platibanda escondendo o } \\
\text { telhado; } \\
\text { - Telhado borboleta; } \\
\text { - Varanda; } \\
\text { - Composição em prisma } \\
\text { retangular e; } \\
\text { - Pergolado. }\end{array}$ & $\begin{array}{l}\text { - Repetição de modelos e } \\
\text { elementos modernistas; } \\
\text { - Emprego dos elementos sem } \\
\text { uma ordenação plástica; } \\
\text { - Menor unidade compositiva } \\
\text { daqueles tidos como } \\
\text { referenciados; } \\
\text { - Variedade de revestimentos, } \\
\text { azulejos, pedras e/ou gesso; } \\
\text { - Pilares circulares e/ou com } \\
\text { formas em "V"; } \\
\text { - Platibandas que escondem a } \\
\text { cobertura em telha de barro ou } \\
\text { fibrocimento. }\end{array}$ & $\begin{array}{l}\text { - Sobreposição de elementos de } \\
\text { vários "estilos"; } \\
\text { - Hibridismo na composição das } \\
\text { fachadas; } \\
\text { - Inexistência de projeto; } \\
\text { - Mimese de elementos } \\
\text { presentes nos exemplares } \\
\text { legítimos; } \\
\text { - Implantação da edificação no } \\
\text { lote (sem recuos); } \\
\text { - Esquadrias (indicavam uma } \\
\text { estrutura independente); } \\
\text { - Telhado inclinado (aparente } \\
\text { ou utilizado platibanda); } \\
\text { - Colunas metálicas; } \\
\text { - Pilotis sem função estrutural; } \\
\text { - Cobertura da varanda com } \\
\text { telhas. }\end{array}$ \\
\hline
\end{tabular}

Ademais, somada às categorias, a presente pesquisa perpassa pelas transformações urbanas do tecido urbano de Anápolis e a configuração paisagística e urbanística do ideário modernista, tendo as habitações como elementos constituintes da dinâmica urbana verificada entre as décadas de 1930-70.

\section{PROCESSOS DE RENOVAÇÃO DA CIDADE DE ANÁPOLIS}

O cenário de mudanças foi possibilitada também pela atuação pública dos engenheiros, notadamente de José Fernandes Valente que nas décadas de 1930 e 1940 modificou as características morfológicas da cidade, alterando, por exemplo, o traçado das praças e determinando, por meio de decreto, demolição de edifícios de caráter colonial. A configuração da cidade com características coloniais passou a ser modernizada pela abertura de novas vias, alargamento das existentes e urbanização das áreas públicas, com destaque às praças da cidade.

Soma-se às iniciativas públicas de urbanização de Anápolis, a difusão do ideário modernista se fortaleceu com as obras de infraestrutura urbana, visando solucionar problemas de saneamento o que representa preocupações de cunho sanitarista e higienista. Influências diretas das discussões sobre urbanismo que vincula-se às correntes progressistas. Com isso, a morfologia urbana presente em Anápolis com feições vernaculares e coloniais foram sendo substituídas por ocupações soltas nos lotes e fachadas com elementos modernistas a partir da década de 1940 tanto no centro da cidade quanto no bairro Jundiaí. Desse modo a ocupação observada por Reis Filho (2004) quanto às casas enfileiradas e a continuidade 
volumétrica foi sendo substituída por recuos, inicialmente, só frontais, com a inserção de jardins e rampas e escadas de acesso à edificação, muitas vezes elevadas do solo.

A apropriação dessas ideias que moldavam os grandes centros urbanos ressoou em Anápolis à medida que a ferrovia permitia a circulação de ideias que foram aplicadas na produção do espaço urbano anapolino. Confere à cidade também relevância no eixo desenvolvimentista do interior de Goiás e enseja a sua importância como entreposto comercial, em que se destacam as atividades atacadistas e fabris desde meados da década de 1940, conforme relatado nos jornais da época ${ }^{1}$.

De uma paisagem urbana colonial e atrasada, a cidade poderia acompanhar as ideias inovadoras e civilizatória, cunhadas por transformações e renovações urbanas ao longo das décadas de 1930-70. Isso se verifica não só em edifícios administrativos, institucionais, como também naqueles de caráter privado, como instituições financeiras e habitações unifamiliares.

A dinâmica econômica da cidade estimulava a instalação de instituições financeiras privadas, muitas vezes administradas pelos próprios comerciantes que buscavam aplicar e ampliar seus negócios. Em sua maioria eram migrantes e à medida que estes migrantes [especialmente árabes] se fixavam na cidade e novas atividades comerciais e industriais iam se estabelecendo, a dinâmica urbana da cidade se consolidava como novos elementos que se distanciavam das características morfológicas da antiga capital do Estado.

As ações de renovação urbana do centro da cidade datam dos anos 1920, período em que se constata a construção de edifícios oficiais com elementos ecléticos, camuflando os telhados coloniais e, ainda, fachadas com referências Art Déco, buscando acompanhar os estilos vigentes nas principais cidades do país. Uma arquitetura didática e modernizadora, que reforçava a vontade de afastar Anápolis das feições coloniais e constituir uma paisagem moderna.

A transformação da cidade é demarcada, segundo Polonial (1995) pela implantação da ferrovia em 1935, tornando-se o eixo de conexão entre o sul do Estado à região mais central e também do Estado com os centros urbanos mais desenvolvidos do país. Com a estrada de ferro, vieram também as ideias modernizadoras por meio da ação privada que via na ferrovia a possibilidade de expansão dos negócios, principalmente pela exportação de produtos agropecuários.

\footnotetext{
${ }^{1}$ Para o desenvolvimento da pesquisa, foram coletadas diversas informações em recortes de jornais da época, onde se registravam empreendimentos imobiliários e a instalação de empresas importantes. Havia uma vontade de exaltar o desenvolvimento e progresso da cidade de Anápolis entre as décadas de 194060.
} 
A cidade de Anápolis era um pequeno povoado que surgiu por volta dos anos 1870 ao redor da Capela Santana, tornando-se cidade em 1907 quando passou assim passou a ser denominada. A população era escassa, havia poucas moradias, que, aos poucos, foram sendo reformadas e construídas em alvenaria, conferindo a cidade feições mais urbanas (POLONIAL, 1995, p. 32).

Entre 1870 e 1935, conforme aponta Polonial (1995), houve a primeira fase de ocupação do território anapolino; período anterior à chegada da ferrovia. A partir de 1935, a expansão urbana do Estado de Goiás é intensificada tanto pela construção da nova Capital, Goiânia quanto pelos trilhos férreos, que marcaram seu desenvolvimento urbano. O surgimento de cidades novas ao longo do leito da ferrovia incentivou o povoamento do território goiano, o qual foi intensificado nas décadas posteriores, após a construção de Goiânia e Brasília.

A parada da ferrovia em Anápolis foi implantada a norte do núcleo original da cidade, culminando na expansão do tecido urbano e a conformação de novas áreas e articulação entre o eixo ferroviário e as estradas que permitiam a conexão entre as cidades do estado e a antiga capital. Isso levou à afirmação de Anápolis como um entreposto comercial, atraindo comerciantes de diversas partes do país e do mundo para se fixarem na cidade. Isso reforçou o caráter comercial da cidade, em que se observam atividades atacadistas desde a década de 1940, em função de Anápolis ter assumido o papel de distribuição das mercadorias para outras cidades, inclusive Goiânia e também impulsionou a instalação das primeiras indústrias a norte da cidade, com atividades têxteis.

Para a instalação da estação ferroviária, foi necessária uma transformação na Praça Americano do Brasil, recebendo tratamento paisagístico e remodelação do seu desenho urbano, visando a constituição de um símbolo e monumento referencial para a sociedade anapolina. Um referencial de integração e realização do desejo de modernização pulsante naquele período (figura 6). 


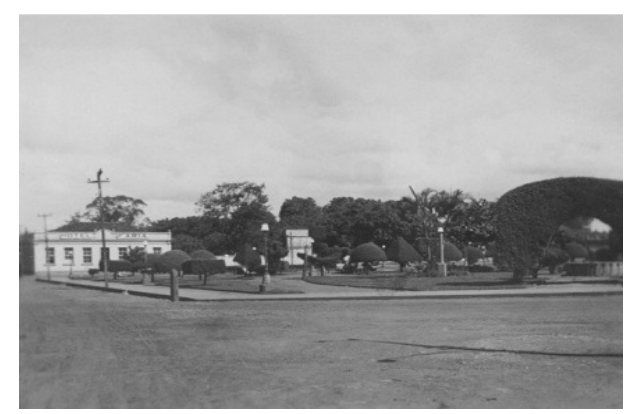

Figura 6: Panorâmica da Praça Americano do Brasil com a Estação Ferroviária ao fundo.

Fonte: Arquivo Museu Histórico de Anápolis, 2011.

Além da Praça Americano do Brasil, a Praça Bom Jesus também recebeu tratamento paisagístico. Os principais edifícios públicos aí implantados passaram por remodelações de caráter modernizador, com destaque à prefeitura com elementos característicos do Art Déco. Essas melhorias urbanas promovidas pela administração municipal, reforçava o desejo de modernização da sociedade, promovendo espaços públicos para a expressão cultural da sociedade, notadamente as festividades.

E foi sobre o traçado ortogonal que foram sendo implantadas edificações com características modernistas, bem como ruas com tratamento paisagístico e urbanístico, definindo-se, por exemplo, as calçadas e o leito carroçável das vias, bem como espaços públicos destinados às atividades sociais, com destaque à Praça Bom Jesus, local em que havia um número significativo de edifícios oficiais com feições modernistas, ainda que caracterizados por elementos Art Déco.

A desejo de modernidade, portanto, foi cunhada pela renovação urbana inicial com edifícios oficiais em Art Déco, a construção de praças com tratamento paisagístico, e o alargamento das vias principais com influências do movimento citybeautiful. O objetivo dessas ações era aliar o desenvolvimento econômico da cidade com o ideário modernista, eliminando quaisquer resíduos de atraso do período colonial. Contribuiu para a renovação urbana a expansão da cidade para leste, ultrapassando os elementos reguladores do crescimento urbano (PANERAI, 2006), notadamente os cursos d'água e a ferrovia como limites iniciais da cidade.

O crescimento da cidade intensificou-se nos arredores da ferrovia, corroborando para uma ocupação no sentido norte-sul, com sua porção central limitada entre os recursos hídricos (figura 7). A expansão urbana concentrou-se entre os limites naturais e o leito férreo, sendo ultrapassado apenas na década seguinte, com a implantação do bairro planejado Jundiaí, localizado a leste. 


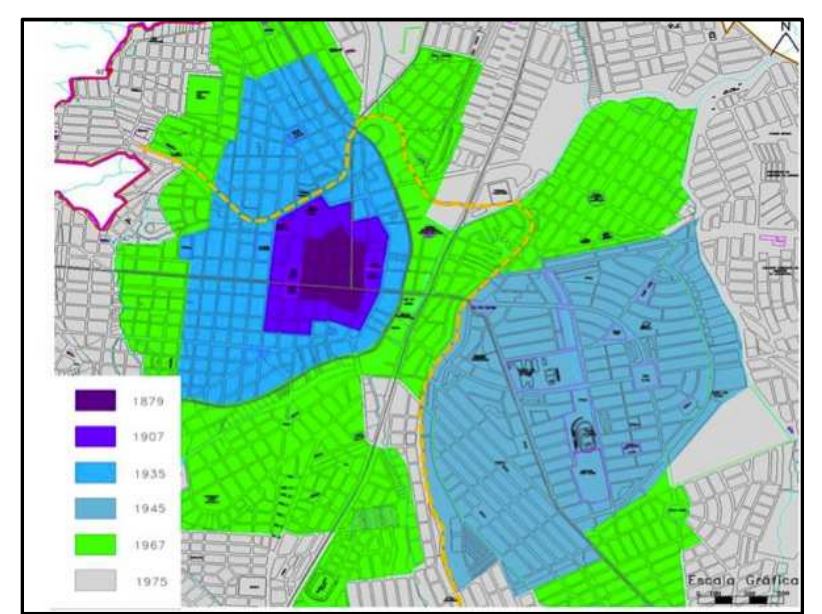

Figura 7: Evolução urbana de Anápolis com destaque ao desenho da ferrovia, implantada em 1935 e sua relação com a configuração urbana da cidade.

Fonte: Plano Diretor 2006, adaptado pelos autores, 2011.

Nesse perímetro, a reconfiguração urbana da cidade ocorreu pelas políticas públicas que buscaram a renovação urbana, promovendo também a expansão da cidade para além de seus limites com a abertura de novas vias: o que permitiu o investimento privado em novos loteamentos urbanos, com destaque ao Bairro Jundiaí. No final dos anos 1940, este bairro-jardim de iniciativa privada marca a expressão máxima de uma transformação em curso: em 1953, foi lançado no mercado a venda dos lotes do Bairro Jundiaí, cujo planejamento urbano previa equipamentos públicos e áreas verdes (figura 8).

Para a implantação do bairro houve obras de infraestrutura urbana para que a conexão como centro ocorresse e, em consequência, permitiu a expansão da cidade a partir de um eixo de crescimento: a Avenida Pedro Ludovico que na época era a principal via de ligação entre Anápolis e Goiânia. O projeto foi elaborado pelo Engenheiro e Urbanista João Alves de Toledo com fortes influências dos bairrosjardins desenvolvidos em São Paulo e Rio de Janeiro na época e o desenho proposto foi criticado pelo Engenheiro ToichiHashigoshi, então recém-chegado à cidade. $\mathrm{Na}$ edição 881 do XV ano do jornal local datado de 15 de Maio de 1949, descreveu o projeto como sendo uma solução racional, funcional e ambientalmente planejada, visando reforçar à cidade sua ímpar característica progressista. 


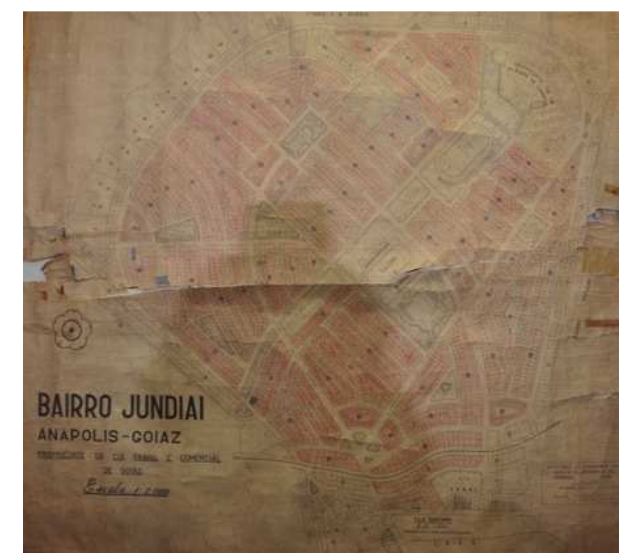

Figura 8: Planta Urbanística do Bairro-Jardim Jundiaí com feições modernistas: quadras orgânicas, espaços públicos e áreas verdes.

Fonte: Museu Histórico de Anápolis, 2011.

O lançamento do bairro-jardim Jundiaí demonstra a influência dos ideias que percorriam os centros urbanos mais consolidados e possibilitava novos arranjos de organização da paisagem anapolina. Também reflete a dinâmica econômica da cidade, permitindo aos migrantes investir no mercado imobiliário. Como resultado da pesquisa de campo, observa-se a presença de parte considerável dos exemplares identificados nesta pesquisa: 52 exemplares com características modernistas distribuídos entre arquitetura referenciada, apropriada e popularizada, dos quais a maior parte encontra-se na segunda categoria. Isso enaltece a relação socioeconômica da época e reforça as expressões de modernidade no interior do país.

Desse modo, a cidade teve um impulso de crescimento urbano no sentido leste, modificando suas feições urbanas: a oeste, foram implantados conjuntos habitacionais para a população de menor poder aquisitivo, enquanto a leste, o Bairro Jundiaí se configurava como nova centralidade urbana, tornando-se um dos maiores bairros da cidade, na atualidade.

A renovação urbana no centro de Anápolis e a implantação do bairro Jundiaí demonstram as modernizações da cidade em termo de traçado urbano, que, somadas às edificações públicas Art Déco - novos edifícios ou remodelações de fachadas dos existentes - e às residências privadas constituíram um tecido urbano nessas duas principais centralidades da cidade.O mapeamento dos exemplares nestes bairros, permite visualizar a difusão do ideário modernista (figura 11).

Nota-se a aproximação entre as ações públicas e as privadas quanto à localização dos exemplares referenciados, muitas vezes, pertencentes à elite da cidade - empresários e comerciantes migrantes. Significa que a pujança econômica proporcionada pela ferrovia permita o investimento de parte da população em edifícios com características modernistas, principalmente na década de 1950. Já no Bairro 
Jundiaí, cuja ocupação ocorreu entre as décadas de 1960-70, observa-se uma maior concentração de arquitetura apropriada, momento que a difusão do ideário modernista se reforçada com a construção de Brasília. Já nas bordas destes bairros, foram observadas a concentração dos exemplares popularizados, indicando a localização de uma parcela da população com menor renda, mas que reproduzira as ideias disseminadas pela elite.

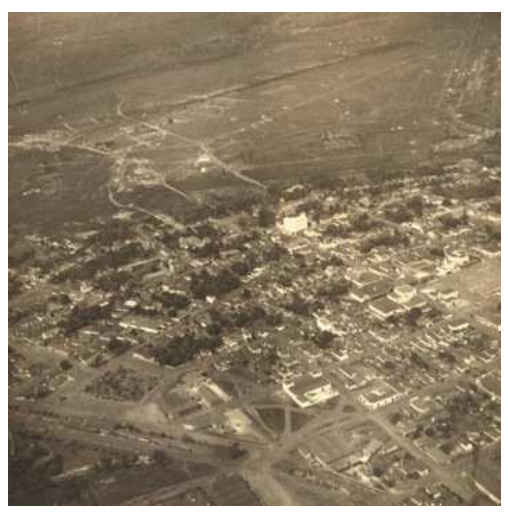

Figura 9: Vista área do centro de Anápolis e as primeiras vias de interligação com o bairro Jundiaí nos anos 1950.

Fonte: Museu Histórico de Anápolis, 2011.

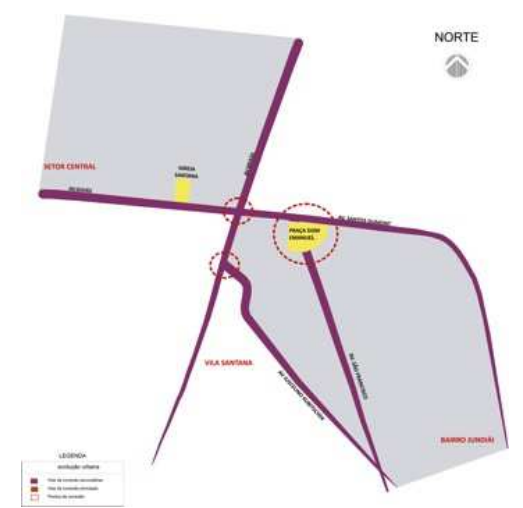

Figura 10: Esquema gráfico de reestruturação urbana da cidade. Abertura de vias. Fonte: Acervo dos autores, 2011. 


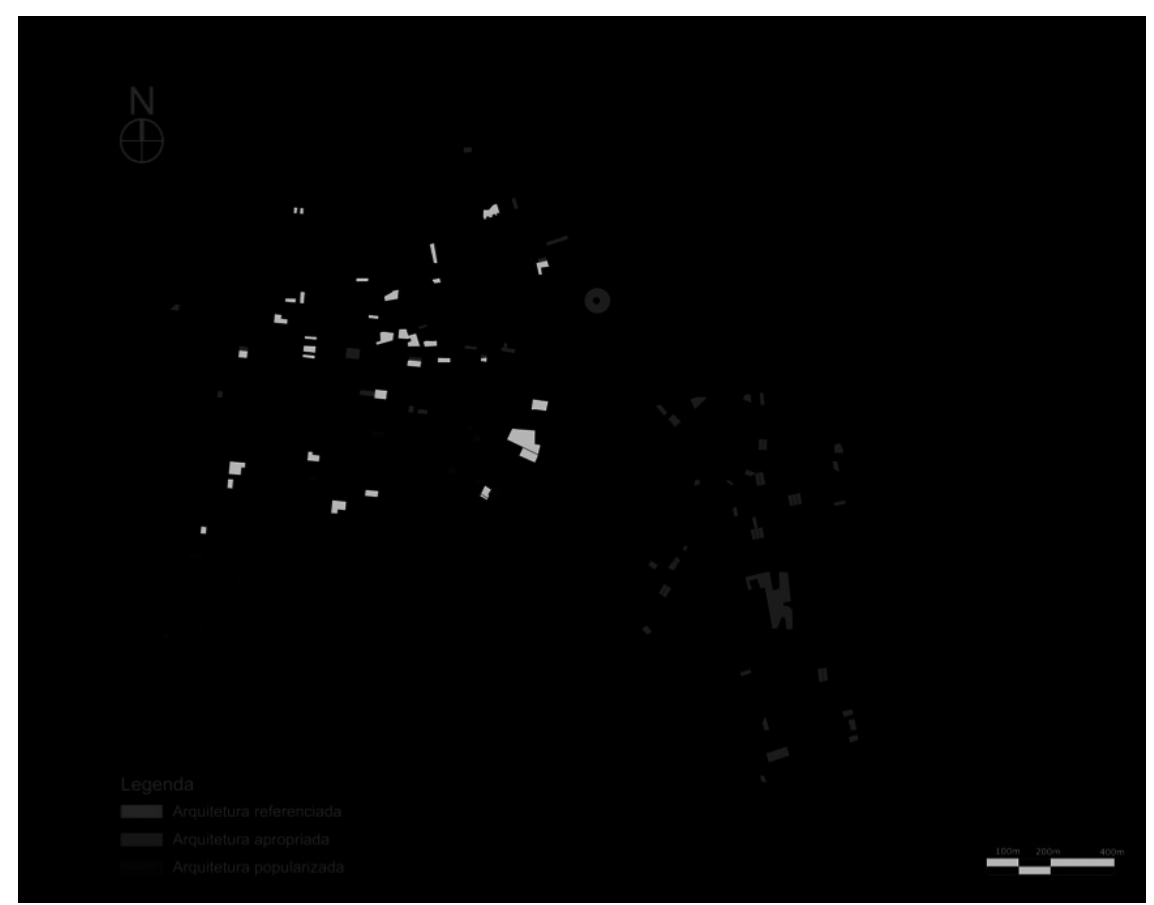

Figura 11: Espacialização dos exemplares modernistas Centro e Bairro Jundiaí, Anápolis (19401970).

Fonte: arquivo dos autores, 2011.

Mediante esse fenômeno, a cidade assistiu a produção de uma arquitetura que carregava em si os elementos modernistas em maior ou menor grau, resultando num conjunto de exemplares referenciados, apropriados e popularizados, discutidos a seguir.

\section{A EXPRESSÃO MODERNISTA NOS EXEMPLARES HABITACIONAIS}

Em Anápolis, o período de maior expressividade da linguagem arquitetônica modernista ocorreu entre as décadas de 1940 e 1960, que coincide com o período de implantação de cidades novas no interior do país, atraindo os olhares de migrantes para a cidade, que carregam consigo as influências deste contexto de otimismo e desenvolvimento, incorporando a feição da arquitetura moderna no cotidiano da cidade, com desdobramentos também na década de 1970, mas já com maior número de exemplares apropriados e popularizados.

A chegada da arquitetura moderna vinda pelos trilhos e pela estrada que levava ao então canteiro de obras que era Brasília alterou, significativamente, a paisagem de Anápolis. A cidade recebeu, com grande aceitação, essa arquitetura modernista. A expressão do ideário modernista está presente nas áreas mais consolidadas do tecido urbano, evidenciando a relação entre as transformações 
urbanas e a inserção dos exemplares levantados. Como a arquitetura moderna trazia arraigada consigo a imagem da renovação, os cidadãos anapolinos se apropriaram e reproduziram de diversas formas a linguagem modernista: ora com mais rigor às características internacionais e nacionais; ora com incorporação de alguns elementos de referência ou pela inserção aleatória de elementos característicos. Essa profusão de elementos arquitetônicos e as mudanças urbanístico-paisagísticas oferecem uma paisagem remodelada e reconfigurada como expressão cultural de um novo olhar para a cidade de Anápolis.

A análise e leitura da evolução urbana da cidade permitiu compreender a dinâmica socioeconômica, além da detecção da difusão do ideal modernista na configuração urbana de Anápolis. Essa leitura também corroborouna delimitação da área de estudo, tendo em vista os processos de evolução e ocupação da malha urbana, considerados como núcleos pioneiros da cidade, e, por conseguinte, uma maior concentração dos exemplares: o centro histórico e o bairro-jardim Jundiaí.

Devido ao distanciamento físico entre o centro-oeste e os principais centros nacionais, as técnicas e tecnologias que foram utilizadas nas construções precisaram se adaptar às existentes no local, com emprego de adobe e pintura caiada. Este fator alterou demasiadamente a concepção, execução e resultado final dos objetos arquitetônicos em que a mescla de características entre tradição e novo consolidaram a fusão entre o vernáculo e o erudito. Estas condições são responsáveis pela regionalização e singularização da arquitetura brasileira, assim, esta foi uma arquitetura que se mostrou ética com o lugar onde foi inserida, adaptou-se ao contexto social e cultural sem deixar de lado o diálogo com o espírito moderno que acometeu o país e com o tempo em que foi produzida, garantindo-lhe assim, legitimidade nas apropriações realizadas.

Com isso, podemos considerar que a arquitetura moderna instaurada na região Centro-Oeste brasileira é uma arquitetura que conserva parte das tradições herdadas das cidades coloniais e, ao mesmo tempo, incorpora a expressão plástica modernista. Em Anápolis, observou-se pelo mapeamento, que os exemplares em sua maioria não possuem autoria mas revelam a incorporação das ideias modernistas por todas as camadas sociais da população, uma vez que há um maior número de exemplares apropriados e popularizados do que os referenciados. Aqueles em áreas mais afastadas dos principais espaços públicos e estes nas imediações das praças e principais edifícios públicos e institucionais.

A distribuição dos exemplares também revela o espraiamento e expansão da cidade para além das duas centralidades, onde os exemplares popularizados são 
mais constantes. Geertz (1997, p.176) chamou este processo de "radical pluralização do produto do pensamento" visto que outrora o movimento moderno concebia idealizações universais e por isso, genéricas. Lembrando Lúcio Costa (GUERRA, 2008) havia o desejo de renovar a arquitetura colonial, sem contudo substituí-la pela arquitetura internacional.

Comparando as primeiras manifestações de arquitetura modernista no Brasil, observa-se que os exemplares referenciados foram construídos posteriormente, mas que apresentam características disseminadas, por exemplo, pelo Ministério da Educação e Saúde (MES) de 1937: a integração com a paisagem e incorporação de outras expressões artísticas. Evidencia-se que estes exemplares possuem o rigor formal e se assemelham às propostas modernistas brasileiras e, portanto, assumem importante papel de difusão desse movimento em Anápolis.

No contexto analisado,verificou-se a concentração de exemplares referenciados de autoria dos principais engenheiros, urbanistas e arquitetos presentes na cidade ao longo das vias principais. Estas configuravam-se como eixos ou linhas de crescimento (PANERAI, 2006): a Rua Engenheiro Portela conecta a Praça Americano do Brasil à Praça Bom Jesus e também à saída para Goiânia; e a Rua Floriano Peixoto interliga o centro com a parte norte da cidade. Nessas duas vias, dispostas paralelas aos espaços públicos renovados, tornaram-se importantes referências de organização espacial e revelam a dinâmica da cidade pela concentração dos exemplares referenciados. Estas edificações são obras singulares representativas da arquitetura modernista de Anápolis e são elaboradas pelos profissionais atuantes na cidade, como Elder Rocha Lima e Lúcio Costa, por exemplo.

A residência da Rua Floriano Peixoto tem na sua organização espacial três lâminas retangulares que se estabelecem nos limites dos lotes configurando um pátiojardim no centro do lote (figura 12). Os positivos cheios destas lâminas, por sua vez possuem azulejos e janelas em fita. A presença de um jardim sob um pergolado configura um intervalo visual entre a rua e o interior da residência. A janela em fita e a platibanda reforçam a predominância da horizontalidade na mesma. Contudo, uma série de vazios interrompe esta leitura, destacando e revelando importantes características. O acesso principal se dá por uma escadaria que termina em um grande patamar encoberto pela platibanda. O jogo de cheios e vazios enaltece a dinâmica compositiva da fachada oeste da edificação faz da apreensão visual de sua forma um constante e atento exercício de percepção (Figura 13). As grandes aberturas na massa suspensa não conseguem fazê-la leve, devido a uniformidade das cores dos revestimentos que se uniformizam com as esquadrias. 
A residência Hanna Hajar (1970-1972) localizada no Centro, na Rua Engenheiro Portela, se destaca pela sua força volumétrica (Figura 14). É um dos mais importantes objetos modernos na paisagem da cidade. Nota-se uma forte influência da arquitetura paulista, onde um prisma pesado de base retangular se ergue e se solta no terreno, onde as massas são acentuadas pelos planos horizontais de concreto.

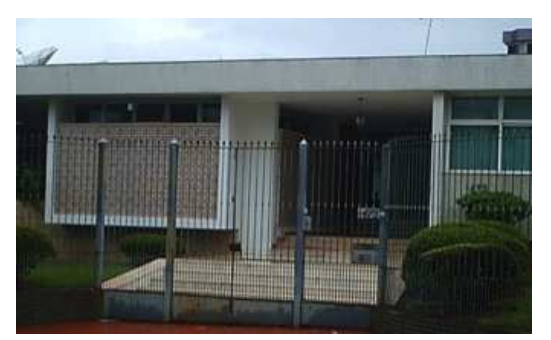

Figura 12: Residência na Rua Floriano Peixoto. Vista Lateral. Fonte: Acervo dos autores, 2011.

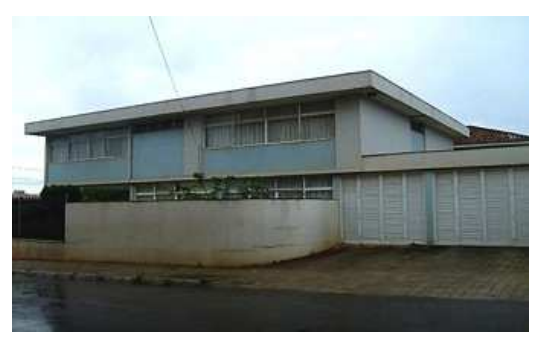

Figura 13: Residência na Rua Floriano Peixoto. Vista Lateral. Fonte: Acervo dos autores, 2011

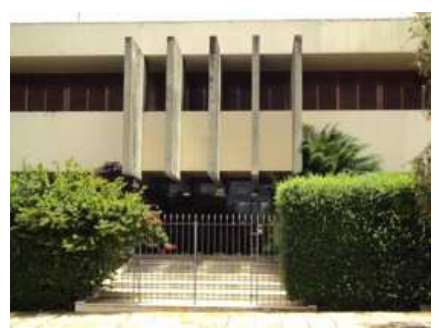

Figura 14: Residência Hanna Hajar. Vista Frontal. Fonte: Acervo dos autores, 2011.

As formas da arquitetura moderna, com seu caráter universal, se proliferaram pelo mundo inteiro. Sua linguagem límpida e de fácil assimilação contribuiu para a apropriação de seus elementos, contudo nem sempre os critérios projetuais da proposta modernista foram seguidos. Significa que arquitetura moderna tornou-se diversificada que, por muitas vezes, afastou-se dos processos compositivos defendidos pelos mestres modernistas. No entanto, de algum modo possuíram, marcadas em sua forma, uma ligação, mesmo que distante, com a linguagem do movimento moderno, sendo possível o reconhecimento de suas características.

A arquitetura moderna apropriada em Anápolis gera uma profusão de elementos sem nenhum critério compositivo. As formas pregnantes e facilmente assimiladas da arquitetura modernista permitiram a ocorrência de uma série de obras que tentavam se aproximar dos exemplares referenciados. Desse modo, a questão simbólica da arquitetura moderna foi mais determinante para a presença dessa arquitetura em Anápolis do que as questões funcionais da nova proposta arquitetônica: o efeito comunicativo das fachadas tornava-se mais importante para a afirmação do ideário do que as soluções funcionais das plantas.

Os construtores da cidade, sejam eles profissionais ou não, se sentiram aptos a reproduzir as formas da arquitetura modernista e os cidadãos comuns, movidos pela ideia de progresso da época,foram incentivados também com o desejo de erguer suas residências com as características modernas. A quantidade de exemplares, que se encaixam na categoria de arquitetura moderna apropriada, é numerosa e se justifica pelo fato de que são obras muitas vezes construídas sem a elaboração de projetos 
arquitetônicos $^{2}$, tornando-as construções acessíveis a uma parcela maior dos cidadãos. Numa deriva pela cidade é possível notar os elementos que se referenciam à arquitetura moderna presentes nos exemplares que contribuem para a formação da paisagem urbanade Anápolis.

A ocorrência desses elementos não se restringe apenas à arquitetura residencial. O aparecimento das características da escola modernista está também presente em edifícios comerciais e institucionais. Na Centro da cidade há uma concentração significativa de edificações nas proximidades da Igreja Bom Jesus, do Córrego das Antas e às margens da Av. Pedro Ludovico. Esse fenômeno se dá, antes de qualquer coisa, pela própria evolução urbana da cidade: a Igreja e a Praça Bom Jesus têm seu entorno consolidado quando da implantação da estação ferroviária em suas imediações; já a Av. Pedro Ludovico era parte da estrada que levava os pioneiros, materiais e suprimentos para Goiânia, em construção na década de 1930.

Nos exemplares pertencentes à categoria apropriada é possível identificar alguns dos principais elementos que foram difundidos pelos profissionais e leigos na construção de edifícios em Anápolis (figuras 15, 16 e 17).

O telhado borboleta, a edificação que se desenvolve acima do nível da rua, a janela em fita, planos de vidro, pilares circulares e uma diversidade de revestimentos, principalmente o azulejo e o gesso são alguns dos elementos popularizados (Figuras 18, 19 e 20). A platibanda é, sem dúvida, o elemento mais difundido e recorrente.

\footnotetext{
${ }^{2}$ Os dados foram coletados em entrevistas e no levantamento de campo, com visitas ao Museu Histórico de Anápolis e do acervo da Prefeitura de Anápolis.
} 


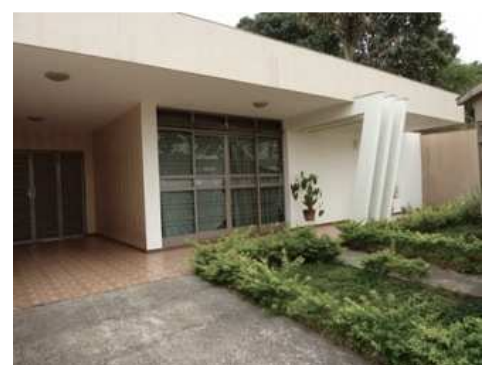

Figura 15:Residência Rua Padre L. dos Santos. Evidencia a distorção do pilar em "V". Fonte: acervo dos autores, 2011.

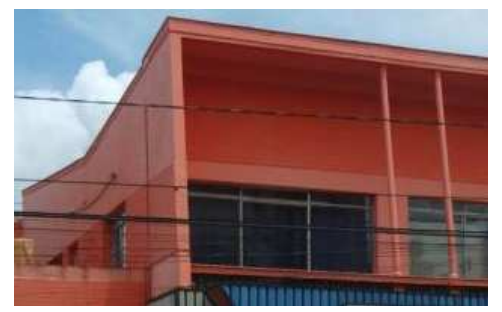

Figura 18: Detalhe do telhado borboleta, da "moldura" da fachada e varanda com pilares circulares. Fonte: acervo dos autores, 2011.

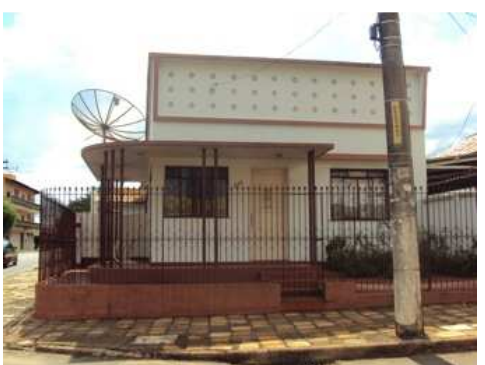

Figura 16:Rua Rui Barbosa, n. 260. Telhado borboleta e pilares cilíndricos na varanda. Fonte: acervo dos autores, 2011.

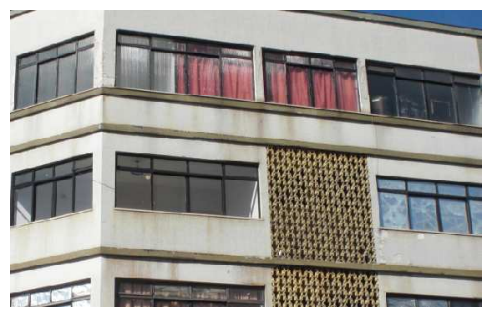

Figura 19: Detalhe das janelas em fita, da emolduração dos pavimentos e do cobogó na parte central destinada a circulação. Fonte: acervo dos autores, 2011.

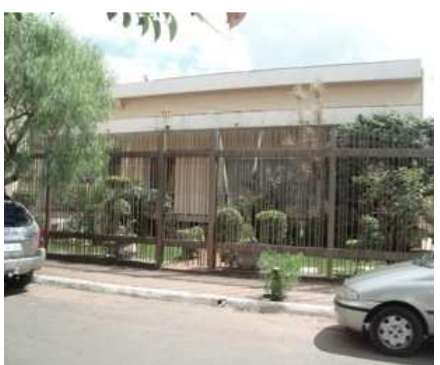

Figura 17:Residência Rua Aquiles Pina, n.51, varanda com pilares metálicos em " $\mathrm{V}$ ". Fonte: acervo dos autores, 2010.

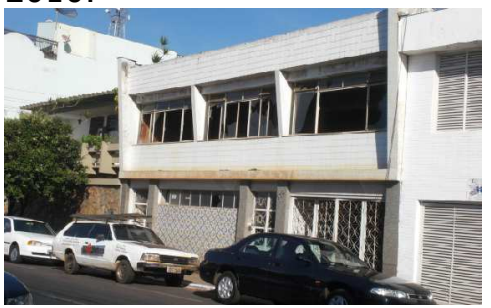

Figura 20: Residência da Rua Coronel Batista em frente ao Museu Histórico de Anápolis. Fonte: acervo dos autores, 2011.

Segawa (1999), Arruda (1999) e Lara (2005) apresentam as diversas manifestações arquitetônicas modernistas no Brasil. Tais especificidades, na maioria dos casos, foram inseridas na práxis arquitetônica por adequação aos condicionantes socioculturais e geográficos das mais diversas localidades do Brasil. Em Anápolis, a partir dos dados coletados, percebemos esses elementos nos exemplares distribuídos entre os bairros Centro e Jundiaí, visando também uma catalogação e um possível panorama dos bens passíveis de constituir um acervo modernista na cidade, ainda não reconhecido.

Na pesquisa de campo, por meio da observação, identificamos os exemplares, constatando sua espacialização no tecido urbano caracterizado anteriormente, aferidos por entrevistas com moradores locais e nos documentos presentes no Museu Histórico de Anápolis, tendo os jornais como importante fonte de pesquisa. Isso porque a precisão das datas de cada um dos exemplares e o pouco interesse dos proprietários em contribuir para a elaboração documental do acervo existente na cidade dificultou um levantamento mais detalhado.

As análises das fachadas dos exemplares e sua implantação no lote possibilitaram uma classificação por categorias dos exemplares residenciais, reconhecendo-se suas estruturais formais de organização espacial, relacionados ao contexto urbano. Isso porque a pesquisa deteve-se na relação entre as escalas urbana e arquitetônica, entendendo os exemplares como elementos de configuração das 
fachadas das ruas, que se modificaram à medida que o ideário modernista se difundia e se consolidada na sociedade anapolina.

Nessa relação, destacamos a presença dessas edificações por todo o território analisado. Fato que deixa claro que essa apropriação das características modernistas aconteceu em todo o tecido consolidado da cidade, ou seja, as ideias modernistas atingiram e se espalharam na cidade como um todo.

A partir da sistematização e das características aferidas a cada uma das categorias, podemos afirmar que há o predomínio das manifestações referenciadas e popularizadas na paisagem anapolina, reforçando o desejo da sociedade em ser moderna. Ademais, os exemplares referenciados datam de períodos posteriores às primeiras manifestações do país, fortemente influenciados pela construção de Brasília, reforçando a hipótese de migração dos profissionais para o interior do Brasil.

Em síntese, podemos afirmar que os exemplares apropriados e referenciados utilizaram-se de técnicas vernáculas e de materiais de construção disponíveis no local, tais como paredes em adobe.As manifestações e a popularização dos elementos desta arquitetura pelas diversas camadas sociais ocorreram pela larga adesão e apreensão deste repertório em que se destacam: telhados invertidos, marquises, uso de azulejos e brise-soleils. Estes elementos de arquitetura são as partes mais visíveis de um edifício e expressam a definição do todo edificado econformam as feições urbanísticapaisagísticas da cidade.

Nos diagramas sintáticos apresentados abaixo podem ser observadas as linhas de força que estruturam a composição formal da fachada, as formas geométricas e os elementos marcantes das fachadas (figura 22), demonstrando a apropriação e popularização do vocabulário modernista na cidade de Anápolis.

Os exemplares popularizados reportam a um arranjo espacial com menor rigor formal em que há uma mistura de elementos estilísticos e evidenciam uma apropriação menos elaborada do ponto de vista estético. Tampouco considera os recuos e as proporções, deixando clara a construção por parte das camadas mais populares ou com menos conhecimento acerca dos princípios modernistas (figura 23).
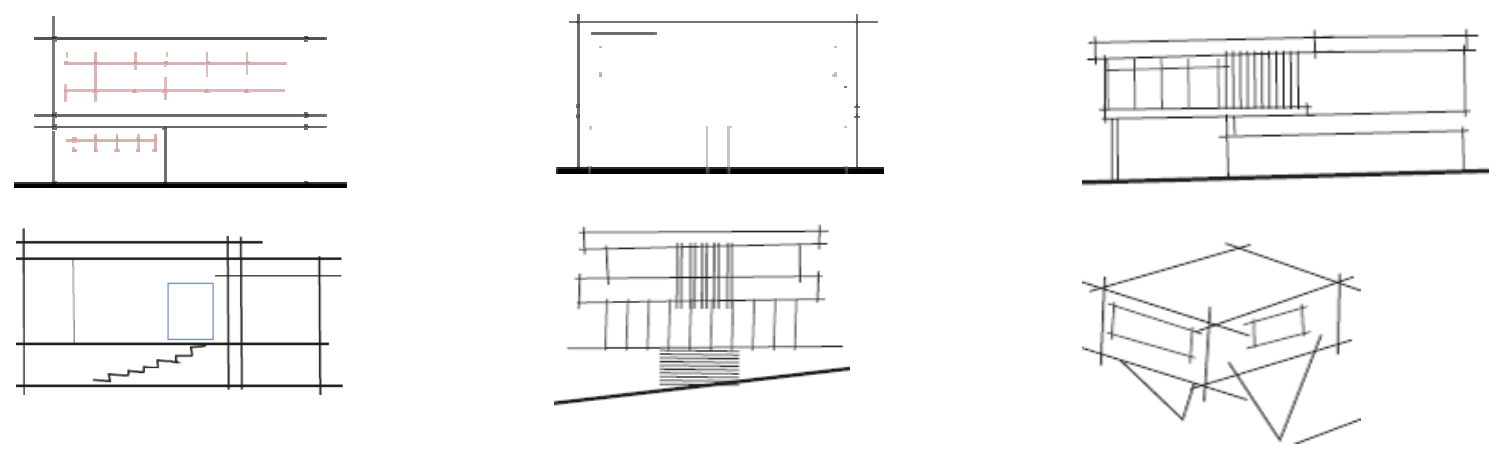

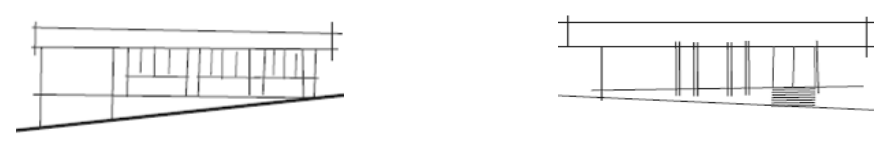

Figura 21: Diagramas sintáticos da composição formal das fachadas.

Fonte: arquivo dos autores, 2011.
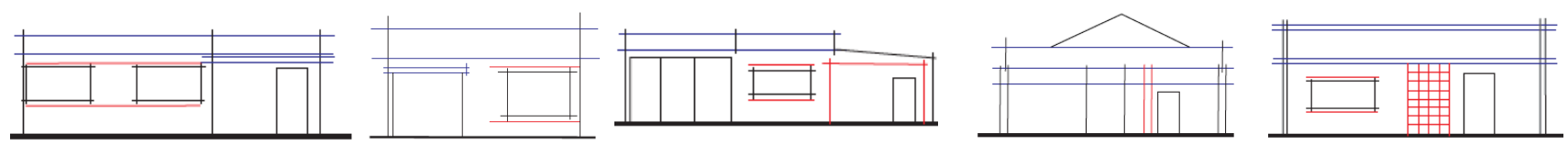

Figura 22: diagramas sintáticos da composição forma das fachadas dos exemplares popularizados. Fonte: Arquivo dos autores, 2011.

\section{CONSIDERAÇÕES FINAIS}

Uma análise geral da área estudada nos mostra alguns detalhes importantes sobre a arquitetura anapolina. A primeira delas, como já foi dito, diz respeito ao núcleo original da cidade, Anápolis "nasceu" e cresceu ao redor primeiro da Praça Santana, núcleo pioneiro da cidade e posteriormente ao redor da Praça Bom Jesus e Americano do Brasil. A primeira pela concentração de edifícios públicos, como a sede da prefeitura; já a segunda em virtude da ferrovia e de sua estação principal, e distante apenas duas quadras da anterior. Nota-se também um grande número de edificações com características Art Déco, influência da década de 1920 e da construção de Goiânia na década seguinte, principalmente no entorno imediato à estação da ferrovia e as praças citadas.

O caráter universal da arquitetura modernista e suas formas se proliferaram pelo mundo inteiro, conseguiram também atingir uma gama significativa de pessoas e camadas sociais. Sua linguagem límpida e de fácil assimilação contribuiu para a larga apropriação de seus elementos. No entanto, nem sempre os critérios projetuais e o rigor formal da proposta modernista foram seguidos. Isso possibilitou falarmos de uma arquitetura moderna apropriada e difundida em meio às características locais de Anápolis, onde pode-se observar a presença das três categorias propostas.

Quanto à renovação urbana, podemos dizer que a difusão do movimento moderno e sua consolidação ocorreram em Anápolis tanto pelas mudanças de sua fisionomia quanto pela constituição de um conjunto de exemplares arquitetônicos, que em diferentes aspectos de apropriação dessas mesmas ideias, anunciavam uma mudança em curso e o desejo de inserir a cidade no processo de interiorização do país, alinhavando-se à linguagem empregada, principalmente, em Brasília. 
Desse modo, houve uma overdose de modernidade e os estilos anteriores, colonial e Art Déco, serviram mais como modelos para expressar o período econômico e cultural pelo qual passava a cidade, via dinâmica dos trilhos. A arquitetura moderna foi, então, reconhecida pelos moradores como um signo de progresso. Com isso houve a modernização das casas nas famílias de classe social superior, engenheirosarquitetos, tecnólogos em edificações e até mesmo práticos, produziram casas inspiradas nos grandes exemplos nacionais e nas famílias de classe mais baixa a apropriação e popularização dos elementos das casas modernas de seus vizinhos se espalhou pela cidade.

Anápolis pode ser considerada uma das muitas localidades brasileiras que também guarda exemplares significativos e relevantes da arquitetura moderna. No entanto, apesar desse legado ser reconhecido, ainda não foram elaborados estudos mais detalhados, que podem indicar a caracterização de um patrimônio edificado de excepcional valor histórico e cultural como registro concreto da importância de Anápolis, situada entre duas principais cidades novas, Goiânia e Brasília, fundadas no período de maior efervescência do modernismo no Brasil.

\section{Referencias}

ARRUDA, Ângelo Marcos Vieira de. Arquitetura em Campo Grande. Campo Grande: Uniderp, 1999.

ARRUDA, Esther Mariano; PEREIRA, Maíra Teixeira. Casas Modernistas em Anápolis. In: Anais $8^{\circ}$ Seminário DoCoMOMo Brasil. Rio de Janeiro: DOCOMOMO, 2009. Disponível no site: http://www.docomomo.org.br/seminario\%208\%20pdfs/072.pdf, acesso em 12/06/2011.

GEERTZ C. O saber local. Novos ensaios em antropologia interpretativa. 5a Ed. Petrópolis: Editora Vozes; 1997.

HASHIGOSHI, Toichi. O nosso principal problema se prende à urbanização. $O$ Anápolis, Anápolis, 15 de maio de 1949.

LARA, Fernando LuisCamargos.Modernismo Popular: elogio ou imitação?In: Cadernos de Arquitetura e Urbanismo, Belo Horizonte, v.12, n.13, p. 171-184, dez. 2005. PEREIRA, Fúlvio Teixeira de Barros. Difusão da Arquitetura Moderna na cidade de João Pessoa (1956-1974). 2008. Dissertação (Mestrado em Arquitetura e Urbanismo). Universidade de São Paulo, São Carlos.

POLONIAL, J. M. Anápolis nos tempos da ferrovia. Goiânia: UFG, 1995. (Dissertação de Mestrado). 
REIS FILHO, Nestor Goulart. Quadro de arquitetura no Brasil. 10 ed. São Paulo: Perspectiva, 2004

SEGAWA, Hugo. Arquiteturas no Brasil 1900-1990. 2 ed. São Paulo: Edusp, 1999. VAZ, Maria Diva Araújo Coelho; ZÁRATE, Maria Heloisa Veloso. A experiência moderna no cerrado goiano. In: Arquitextos (São Paulo. Online), São Paulo, SP, v. 01, p. 067-341, 2005. 